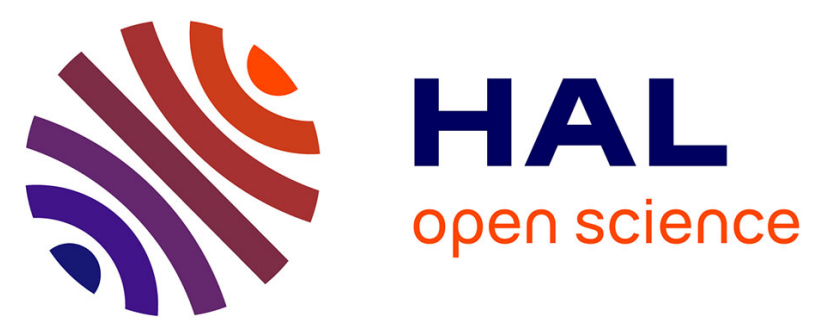

\title{
Assessment of a Multiplex PCR for the Simultaneous Diagnosis of Intestinal Cryptosporidiosis and Microsporidiosis
}

Maxime Moniot, Céline Nourrisson, Charlotte Faure, Frédéric Delbac, Loïc Favennec, Frédéric Dalle, Cyril Garrouste, Philippe Poirier

\section{To cite this version:}

Maxime Moniot, Céline Nourrisson, Charlotte Faure, Frédéric Delbac, Loïc Favennec, et al.. Assessment of a Multiplex PCR for the Simultaneous Diagnosis of Intestinal Cryptosporidiosis and Microsporidiosis. Journal of Molecular Diagnostics, 2021, 23 (4), pp.417-423. 10.1016/j.jmoldx.2020.12.005 . hal-03238779

\section{HAL Id: hal-03238779}

https://hal-normandie-univ.archives-ouvertes.fr/hal-03238779

Submitted on 31 May 2021

HAL is a multi-disciplinary open access archive for the deposit and dissemination of scientific research documents, whether they are published or not. The documents may come from teaching and research institutions in France or abroad, or from public or private research centers.
L'archive ouverte pluridisciplinaire HAL, est destinée au dépôt et à la diffusion de documents scientifiques de niveau recherche, publiés ou non, émanant des établissements d'enseignement et de recherche français ou étrangers, des laboratoires publics ou privés. 


\title{
Assessment of a Multiplex PCR for the Simultaneous Diagnosis of Intestinal Cryptosporidiosis and Microsporidiosis
}

\section{Epidemiologic Report from a French Prospective Study}

\author{
Maxime Moniot, ${ }^{* \dagger}$ Céline Nourrisson, ${ }^{* \dagger}$ Charlotte Faure, ${ }^{*}$ Frédéric Delbac, ${ }^{\dagger}$ Loïc Favennec, ${ }^{\ddagger}$ Frédéric Dalle, ${ }^{\S}$ Cyril Garrouste, \\ and Philippe Poirier* ${ }^{\star}$ \\ From the Laboratory of Parasitology and Mycology, * Department of Nephrology, "Centre Hospitalier Universitaire de Clermont-Ferrand, Infection \\ Inflammation et Interaction Hôtes Pathogènes, Clermont-Ferrand; the Université Clermont Auvergne, ${ }^{\dagger}$ Centre National de la Recherche Scientifique, \\ Laboratoire Microorganismes: Génome et Environnement, Clermont-Ferrand; the Laboratory of Parasitology and Mycology, ${ }^{\ddagger}$ Centre Hospitalier \\ Universitaire Rouen, Rouen; and the Laboratory of Parasitology and Mycology, ${ }^{\S}$ Centre Hospitalier Universitaire Dijon, Dijon, France
}

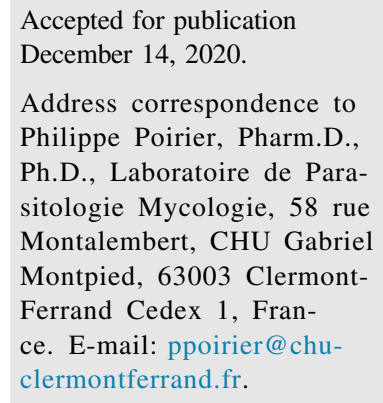

\begin{abstract}
Microsporidiosis and cryptosporidiosis are associated with chronic diarrhea in immunocompromised patients. The objectives of this study were to: i) assess a multiplex quantitative PCR assay targeting Cryptosporidium spp and the microsporidian Enterocytozoon bieneusi and Encephalitozoon spp, and ii) provide an update on the epidemiology of these pathogens. A prospective study was conducted from January 2017 to January 2019. Performance of the assay was assessed, and all cryptosporidia and microsporidia isolates were genotyped. The sensitivity of the multiplex PCR method reached 1 copy/ $\mu \mathrm{L}$ for each targeted pathogen. The sensitivity of co-proantigen testing in the diagnosis of cryptosporidiosis was $73 \%$. The sensitivity of microscopy in the diagnosis of cryptosporidiosis was $64 \%$, and microsporidiosis, 50\%. Among the 456 patients included, 14 were positive for Cryptosporidium spp ( 4 different species); 5, for E. bieneusi; and 2, for Encephalitozoon intestinalis. The overall prevalence of cryptosporidia was $3.1 \%$, and of microsporidia, $1.5 \%$; in kidney transplant recipients $(n=82)$, corresponding values were $7.3 \%$ and $2.4 \%$ ( 6 and 2 patients), respectively. Two cases of $E$. intestinalis infection were diagnosed in children who had traveled to the tropics. This study is the first to assess a multiplex quantitative PCR method for the simultaneous diagnosis of intestinal microsporidiosis and cryptosporidiosis. The highest prevalences of both pathogens were observed in kidney transplant recipients. (J Mol Diagn 2021, 23: 417-423; https://doi.org/10.1016/j.jmoldx.2020.12.005)
\end{abstract}

Microsporidia and cryptosporidia are intracellular eukaryotic pathogens involved in diarrhea, and less frequently in extraintestinal disease, in a wide range of animals. Among the 38 species of Cryptosporidium, 20 are causative agents of diarrhea in humans, with Cryptosporidium parvum and Cryptosporidium hominis representing about $90 \%$ of isolates. ${ }^{1,2}$ The most frequent microsporidian species found in humans are Enterocytozoon bieneusi (>90\% of cases) and Encephalitozoon intestinalis. Both intestinal microsporidiosis and cryptosporidiosis are associated with chronic diarrhea in immunocompromised patients. They were a frequent cause of opportunistic diarrhea in AIDS patients until the availability of antiretroviral therapies. ${ }^{3}$ Today, these infections emerge in solid organ transplant recipients and in patients with hematologic malignancies. ${ }^{3,4}$ Immunocompetent patients may also be infected, although most of these cases are asymptomatic or resolve spontaneously. ${ }^{3,4}$

In medical laboratories, microsporidiosis and cryptosporidiosis are mainly diagnosed using light microscopy

Supported by internal laboratory funding.

Disclosures: None declared. 
with staining-based techniques. However, these methods are time-consuming, are difficult to read, harbor variable performance, and may lack specificity and sensitivity. Several PCR assays targeting Cryptosporidium spp, or the microsporidian E. bieneusi and/or E. intestinalis, have been developed. ${ }^{5-8}$ However, physicians frequently request the diagnosis of cryptosporidiosis and microsporidiosis simultaneously, given that the epidemiology, symptoms, and risk factors are the same. Therefore, the present study aimed to develop multiplex quantitative real-time (q)-PCR targeting, in a single reaction, Cryptosporidium spp, E. bieneusi, and Encephalitozoon spp. All isolates positive for microsporidia and/or cryptosporidia were investigated using epidemiologic analysis, species identification, and genotyping.

\section{Materials and Methods}

\section{Clinical Samples}

Between January 2017 and January 2019, stool samples were collected from different wards of the teaching hospital at Clermont-Ferrand (France). Diagnosis was performed in immunocompromised patients presenting with soft or liquid stools, systematically in children, and in nonimmunocompromised adults when prescribed by a clinician. Specificity assays of the multiplex qPCR were performed using samples positive for 16 other intestinal parasites (Supplemental Table S1).

\section{Microscopic Examination and Co-Proantigen Testing}

From January to December 2017, cryptosporidia were identified using microscopy (Bailenger concentration method followed by Ziehl staining), the RIDAQuick Cryptosporidium co-proantigen test (R-Biopharm, Pfungstadt, Germany), and multiplex qPCR. ${ }^{9}$ For the identification of microsporidia, Trichrome staining and multiplex qPCR were performed. ${ }^{10}$

\section{DNA Extraction}

Two hundred milligrams of stool was introduced in vials containing $800 \mu \mathrm{L}$ of easyMAG lysis buffer (bioMérieux, Craponne, France) and $100 \mu \mathrm{L}$ of $0.5 \mathrm{~mm}$ glass beads (Next Advance, Vincennes, France). Then, a bead beating step was performed for 3 minutes at $3000 \mathrm{~Hz}$ (TissueLyser; Qiagen, Hilden, Germany), followed by a centrifugation for 10 minutes at $20,000 \times g$. Two hundred microliters of supernatant spiked with $5 \mu \mathrm{L}$ of DiaControlDNA DNA virus (Diagenode, Liège, Belgium) was used for DNA extraction using the ELITe InGenius system (ELITechGroup, Puteaux, France), with a final elution volume of $50 \mu \mathrm{L}$.

\section{Multiplex Quantitative PCR}

The detection of Cryptosporidium spp, E. bieneusi, and Encephalitozoon spp was performed using primers and probes previously described (Table 1).,6,11 PCR was performed in a final volume of $25 \mu \mathrm{L}$ containing $5 \mu \mathrm{L}$ of DNA, primers/probes targeting Cryptosporidium spp, E. bieneusi, and E. intestinalis (Table 1), $2.5 \mu \mathrm{L}$ of DiaControlDNA primers/probe mix (Diagenode), and $12.5 \mu \mathrm{L}$ of Amplidiag master mix (Mobidiag, Espoo, Finland). Realtime PCR was performed on the ELITe InGenius system. The amplification consisted of an initial denaturation step of 5 minutes at $95^{\circ} \mathrm{C}$, followed by 40 cycles of denaturation at $95^{\circ} \mathrm{C}$ for 15 seconds, and annealing/elongation at $60^{\circ} \mathrm{C}$ for 1 minute.

\section{Plasmid Preparation for qPCR Sensitivity Assessment}

Briefly, Cryptosporidium spp, E. bieneusi, and E. intestinalis target sequences were cloned into pGEM-T Easy Vector (Promega, Madison, WI) and transfected into Escherichia coli $\mathrm{DH} 5 \alpha$. For each plasmid containing target sequence, serial dilutions containing $10^{2}$ to $10^{6}$ copies $/ \mu \mathrm{L}$ were tested in triplicate. Templates containing mixed targets were analyzed using plasmid mixtures in different proportions: 10/100/1000-fold greater than each other. Each reaction was performed in triplicate.

\section{Species Identification and Genotyping of Cryptosporidium Species}

Species identification was performed by the French National Reference Center for Cryptosporidiosis (Dijon, France) using sequencing of the gp60 encoding gene, as previously described (Table 1). ${ }^{8,12}$

\section{Genotyping of Enterocytozoon bieneusi Isolates and Identification of the Encephalitozoon Species}

Encephalitozoon spp were identified and E. bieneusi genotyped by sequencing the internal transcribed spacer region as previously described (Table 1). ${ }^{13,14}$

\section{DNA Sequence Analyses}

PCR products were sequenced in both strands (GATC Biotech/Eurofins Genomics, Brussels, Belgium). The sequences were submitted to the NCBI database using the nucleotide Basic Local Alignment Search Tool (http://www. ncbi.nlm.nih.gov/BLAST, last accessed April 30, 2020) and genotypes/species were identified using determination of the exact match or closest similarity against deposited sequences. 
Table 1 Primers and Probes Used in This Study

\begin{tabular}{|c|c|c|c|c|c|}
\hline \multirow{2}{*}{$\frac{\text { Method }}{\text { Multiplex qPCR }}$} & \multirow{4}{*}{$\begin{array}{l}\text { Target (gene) } \\
\text { Cryptosporidium } \\
\text { spp (small } \\
\text { subunit rRNA) }\end{array}$} & \multicolumn{2}{|c|}{ Primers and probes } & \multirow{2}{*}{$\begin{array}{l}\text { Final } \\
\text { concentration, } \\
\mu \mathrm{mol} / \mathrm{L} \\
0.2\end{array}$} & \multirow{2}{*}{$\begin{array}{l}\text { Reference } \\
\text { Mary et } \mathrm{al}^{11}\end{array}$} \\
\hline & & Forward & $\overline{5^{\prime}-\text { CATGGATAACCGTGGTAAT-3' }}$ & & \\
\hline & & Reverse & $5^{\prime}-$ TACCCTACCGTCTAAAGCTG-3' & 0.4 & \\
\hline & & Probe & $\begin{array}{l}5^{\prime} \text {-FAM-CTAGAGCTAATACATGCGAAAAAA- } \\
\text { MGB-BHQ1-3' }\end{array}$ & 0.1 & \\
\hline & $\begin{array}{l}\text { Enterocytozoon } \\
\text { bieneusi (small } \\
\text { subunit-rRNA) }\end{array}$ & Probe & $\begin{array}{l}5^{\prime}-\text { YY- } \\
\quad \text { ACGTGGGCGGGAGAAATCTTAGTGTTCGGG } \\
\text {-BHQ1-3' }\end{array}$ & 0.1 & $\begin{array}{r}\text { Menotti } \\
\text { et } \mathrm{al}^{5}\end{array}$ \\
\hline & \multirow{2}{*}{$\begin{array}{l}\text { Encephalitozoon } \\
\text { spp (small } \\
\text { subunit-rRNA) }\end{array}$} & FEI1 & $5^{\prime}$-GCAAGGGAGGAATGGAACAGAACAG- $3^{\prime}$ & 0.2 & \multirow{2}{*}{$\begin{array}{r}\text { Menotti } \\
\text { et } \mathrm{al}^{6}\end{array}$} \\
\hline & & REI1 & $5^{\prime}$-CACGTTCAGAAGCCCATTACACAGC-3' & 0.2 & \\
\hline identification & \multirow{2}{*}{$\begin{array}{l}\text { Cryptosporidium } \\
\text { spp (small } \\
\text { subunit-rRNA) }\end{array}$} & CRU18SR & $\begin{array}{l}5^{\prime} \text {-CTGCTTTAAGCACTCTAATTTTCTCAAAG- } \\
\quad 3^{\prime}\end{array}$ & 0.9 & \multirow{8}{*}{$\begin{array}{l}\text { Hadfield } \\
\text { et } \mathrm{al}^{8}\end{array}$} \\
\hline & & CRU18STM & $\begin{array}{l}5^{\prime}-\mathrm{FAM}-\mathrm{TACGAGCTTTTTAACTGCAACAA-} \\
\text { MGB-NFQ-3' }\end{array}$ & 0.1 & \\
\hline & Cryptosporidium & CRULib13F & 5'-TCCTTGAAATGAATATTTGTGACTCG-3' & 0.9 & \\
\hline & \multirow{5}{*}{$\begin{array}{l}\text { parvum (LIB13) } \\
\text { Cryptosporidium } \\
\text { hominis (LIB13) }\end{array}$} & CRULib13RCp & 5'-TTAATGTGGTAGTTGCGGTTGAAC-3' & 0.9 & \\
\hline & & CRULib13TMCp & $\begin{array}{l}5^{\prime} \text {-VIC-TATCTCTTCGTAGCGGCGTA-MGB- } \\
\text { NFQ-3' }\end{array}$ & 0.15 & \\
\hline & & CRULib13F & 5'-TCСTTGAAATGAATATTTGTGACTCG-3' & 0.9 & \\
\hline & & CRULib13RCh & 5'-AAATGTGGTAGTTGCGGTTGAAA-3' & 0.3 & \\
\hline & & CRULib13TMCh & $\begin{array}{l}5^{\prime} \text {-VIC-CTTACTTCGTGGCGGCGT-MGB- } \\
\text { NFQ-3' }\end{array}$ & 0.1 & \\
\hline & E. bieneusi (ITS) & AL4040 & 5'-AGTGATCCTGTATTAGGGATATT-3' & 0.5 & $\begin{array}{l}\text { Sulaiman } \\
\text { et } \mathrm{al}^{13}\end{array}$ \\
\hline \multirow{4}{*}{$\begin{array}{l}\text { Encephalitozoon } \\
\text { spp } \\
\text { identification }\end{array}$} & \multirow{4}{*}{$\begin{array}{l}\text { Encephalitozoon } \\
\text { spp (ITS) }\end{array}$} & MSP-1 & $5^{\prime}-\mathrm{TGAATGKGTCCCTGT-3'}$ & 1 & \multirow{4}{*}{$\begin{array}{l}\text { Katzwinkel- } \\
\text { Wladarsch } \\
\text { et } \mathrm{al}^{14}\end{array}$} \\
\hline & & MSP-2A & $5^{\prime}-\mathrm{TCACTCGCCGCTACT-3^{ \prime }}$ & 1 & \\
\hline & & MSP-3 & $5^{\prime}$-CACACCGCCCGTCRYTAT-3' & 1 & \\
\hline & & MSP-4A & 5'-CTATGTTAAGTYMAARGGGT-3' & 1 & \\
\hline
\end{tabular}

BHQ, black hole quencher; FAM, 6-carboxyfluorescein; ITS, internal transcribed spacer; MGB, minor groove binding; NFQ, nonfluorescent quencher; qPCR, quantitative PCR; rRNA, ribosomal RNA; TR, Texas Red; VIC, VIC fluorescent dye; YY, Yakima Yellow.

\section{Results}

\section{Performance of the Multiplex qPCR Assay}

The lower limit of detection of the multiplex qPCR assay was set at 1 copy $/ \mu \mathrm{L}$ for each target. Reproducibility was assessed from 30 independent experiments, with CVs of $4.14 \%$ for Cryptosporidium spp, $4.35 \%$ for E. bieneusi, and $4.82 \%$ for E. intestinalis. A target amount as low as $10^{2}$ copies $/ \mu \mathrm{L}$ was still detected for each of the three targets when mixed with $10^{5}$ copies $/ \mu \mathrm{L}$ of both other targets, even though an increased $\mathrm{Ct}$ value was observed (Supplemental Table S2). No cross-reaction was observed with the other intestinal parasite tested (Supplemental Table S1). Interestingly, the primers and probe used for detecting E. intestinalis also detected the DNA of Encephalitozoon cuniculi and Encephalitozoon hellem. Such cross-reactions were expected given that DNA alignment revealed that the target region was highly conserved between the three Encephalitozoon spp (Supplemental Figure S1).

\section{Positive Sample Analysis}

Over the 2 years (from January 2017 to January 2019), 595 stool samples, corresponding to 456 patients, were tested for 
Table 2 Epidemiologic Features of the Studied Population

\begin{tabular}{|c|c|c|c|}
\hline \multirow{2}{*}{$\frac{\text { Feature }}{\text { Number of patients }}$} & & \multicolumn{2}{|l|}{ Value } \\
\hline & & 456 & $100 \%$ \\
\hline \multirow[t]{3}{*}{ Age } & Median (range), years & $55(0-95)$ & \\
\hline & $<10$ years & 64 & $14.0 \%$ \\
\hline & $>75$ years & 54 & $11.8 \%$ \\
\hline \multirow[t]{2}{*}{ Sex } & Male & 260 & $57.0 \%$ \\
\hline & Female & 196 & $43.0 \%$ \\
\hline Immunocompetent patients & & 187 & $41.0 \%$ \\
\hline Immunocompromised patients & & 269 & $59.0 \%$ \\
\hline \multirow[t]{6}{*}{ SOT } & Total & 107 & $23.5 \%$ \\
\hline & Kidney & 82 & $18.0 \%$ \\
\hline & Heart & 10 & $2.2 \%$ \\
\hline & Lung & 3 & $0.7 \%$ \\
\hline & Liver & 11 & $2.4 \%$ \\
\hline & Kidney/liver & 1 & $0.2 \%$ \\
\hline \multirow[t]{3}{*}{ HIV } & Total & 24 & $5.3 \%$ \\
\hline & CD4 count median (range), cells $/ \mathrm{mm}^{3}$ & 239 (3 to 1473) & \\
\hline & Viral load median (range), copies/mL & $0\left(0\right.$ to $\left.10^{6}\right)$ & \\
\hline \multirow[t]{7}{*}{ Hematologic malignancy } & Total & 92 & $20.2 \%$ \\
\hline & HSCT & 37 & $8.1 \%$ \\
\hline & AML & 28 & $6.1 \%$ \\
\hline & Lymphoma & 28 & $6.1 \%$ \\
\hline & ALL & 7 & $1.5 \%$ \\
\hline & MDS & 7 & $1.5 \%$ \\
\hline & Other & 22 & $4.8 \%$ \\
\hline Other immunosuppression & & 46 & $10.1 \%$ \\
\hline Travelers & & 43 & $9.4 \%$ \\
\hline
\end{tabular}

ALL, acute lymphoid leukemia; AML, acute myeloid leukemia; CLL, chronic lymphocytic leukemia; HIV, human immunodeficiency virus; HSCT, hematopoietic stem cell transplantation; MDS, myelodysplastic syndrome; SOT, solid organ transplant recipients.

both microsporidia and cryptosporidia. Epidemiologic features are summarized in Table 2. The male/female ratio was 1.33 and the median age was 55 years, with $14.0 \%$ of children aged $<10$ years old. Immunocompromised patients represented $59.0 \%$ of the cohort, with three main groups: solid organ transplant recipients $(23.5 \%)$, patients with hematologic malignancies (20.2\%), and HIV patients (5.3\%). Thirty-six stool samples were found positive on multiplex qPCR, including 24 for Cryptosporidium spp, 10 for $E$. bieneusi, and 2 for E. intestinalis (species confirmed on internal transcribed spacer sequencing), representing 14 $(3.07 \%), 5(1.10 \%)$, and $2(0.44 \%)$ patients, respectively (Table 3). Therefore, $4.17 \%$ of patients were found to be positive for infection with at least one of the three pathogens. One patient was first positive for E. bieneusi and later for Cryptosporidium spp; and another was positive for both pathogens at the same time. Among positive patients, 13 (68\%) were immunocompromised, including 9 solid organ transplant recipients (47\%; 7 kidney and 2 liver), 2 with hematologic malignancies (11\%) who underwent hematopoietic stem cell transplantation, and 2 HIV patients (11\%) with a $\mathrm{CD}_{4}$ count of $<200$ cells $/ \mathrm{mm}^{3}$ and a high viral load (Table 4). Among the 6 immunocompetent, positive patients, 4 were children aged 5 months to 13 years and had traveled to Mayotte (1 case with $C$. hominis), Mayotte and Burkina Faso ( 2 cases with E. intestinalis), and Burundi (1 case with both Cryptosporidium spp and E. bieneusi). No travel history or other relevant information was found in the 2 other immunocompetent patients positive for $C$. parvum and C. hominis.

\section{Comparison of Diagnostic Methods}

Over the year 2017, stool samples $(n=80)$ were tested using microscopy, co-proantigen testing, and multiplex qPCR. During this period, 11 samples were found to be

Table 3 Results of the Multiplex qPCR Diagnosis During the 2Year Study

\begin{tabular}{lcc}
\hline & $\begin{array}{l}\text { Patients, } \\
\text { number }(\%)\end{array}$ & $\begin{array}{l}\text { Stool sample, } \\
\text { number }(\%)\end{array}$ \\
\hline Total & $456(100)$ & $595(100)$ \\
Positive & $19\left(4.17^{*}\right)$ & $36(6.05)$ \\
Cryptosporidium spp & $14(3.07)$ & $24(4.03)$ \\
Enterocytozoon bieneusi & $5(1.10)$ & $10(1.68)$ \\
Encephalitozoon spp & $2(0.44)$ & $2(0.34)$ \\
\hline
\end{tabular}

${ }^{*}$ Two patients were positive for both Cryptosporidium spp and $E$. bieneusi. qPCR, quantitative PCR. 
Table 4 Epidemiologic Features of Positive Patients for Cryptosporidium spp and/or Microsporidia

\begin{tabular}{|c|c|c|c|c|c|c|c|c|c|}
\hline \multirow{2}{*}{$\begin{array}{l}\text { Features } \\
\text { Number of patients } \\
\text { Age }\end{array}$} & \multicolumn{3}{|c|}{ Overall values } & \multicolumn{2}{|c|}{ Cryptosporidium spp } & \multicolumn{2}{|c|}{$\begin{array}{l}\text { Enterocytozoon } \\
\text { bieneusi }\end{array}$} & \multicolumn{2}{|c|}{$\begin{array}{l}\text { Encephalitozoon } \\
\text { spp }\end{array}$} \\
\hline & 19 & $100 \%$ & $14^{*}$ & $100 \%$ & $5^{*}$ & $100 \%$ & 2 & $100 \%$ & \\
\hline & $<10$ years & 4 & $21 \%$ & 2 & $14 \%$ & 2 & $40 \%$ & 1 & $50 \%$ \\
\hline Sex & Male & 8 & $42 \%$ & 6 & $43 \%$ & 2 & $40 \%$ & 1 & $50 \%$ \\
\hline $\begin{array}{l}\text { Immunocompromised } \\
\text { patients }\end{array}$ & 13 & $68 \%$ & 10 & $71 \%$ & 4 & $80 \%$ & 0 & $0 \%$ & \\
\hline \multirow[t]{2}{*}{ SOT } & Total & 9 & $47 \%$ & 6 & $43 \%$ & 4 & $80 \%$ & 0 & $0 \%$ \\
\hline & Kidney & 7 & $37 \%$ & 6 & $43 \%$ & 2 & $40 \%$ & n.a. & n.a. \\
\hline HIV & $\begin{array}{c}\text { Viral load } \\
\text { (copies/mL) }\end{array}$ & $\begin{array}{c}41,088(892 \\
-81,283)\end{array}$ & n.a. & $\begin{array}{c}41,088(892 \\
-81,283)\end{array}$ & n.a. & n.a. & n.a. & n.a. & n.a. \\
\hline \multirow[t]{4}{*}{ HM } & Total & 2 & $11 \%$ & 2 & $14 \%$ & 0 & $0 \%$ & 0 & $0 \%$ \\
\hline & AML & 1 & $5 \%$ & 1 & $7 \%$ & n.a. & n.a. & n.a. & n.a. \\
\hline & Lymphoma & 1 & $5 \%$ & 1 & $7 \%$ & n.a. & n.a. & n.a. & n.a. \\
\hline & HSCT & 2 & $11 \%$ & 2 & $14 \%$ & n.a. & n.a. & n.a. & n.a. \\
\hline Travelers & & 7 & $37 \%$ & 5 & $36 \%$ & 1 & $20 \%$ & 2 & $100 \%$ \\
\hline
\end{tabular}

${ }^{*}$ Two patients were positive for both Cryptosporidium spp and E. bieneusi.

AML, acute myeloid leukemia; HM, hematologic malignancies; HSCT, hematopoietic stem cell transplantation; n.a., not applicable; SOT, solid organ transplant.

positive for Cryptosporidium spp, and 4, for E. bieneusi. With the multiplex qPCR as a reference, co-proantigen testing and microscopy for the diagnosis of cryptosporidiosis had sensitivity values of $73 \%$ and $64 \%$, respectively. The sensitivity of microscopy for microsporidiosis was $50 \%$. No microscopy-positive/qPCR-negative samples were recorded. Co-proantigen testing for Cryptosporidium was positive in 2 samples that tested negative on microscopy. However, Cryptosporidium co-proantigen testing failed to detect 1 microscopy-positive stool sample (further identified as C. parvum).

\section{Species Identification and Genotyping}

Among the 14 Cryptosporidium spp-positive isolates, 8 C. parvum, 2 C. hominis, 1 Cryptosporidium felis, and 1 Cryptosporidium meleagridis were identified. The latter 2 isolates were not identified at the species level (Supplemental Table S3). Genotyping of the 8 C. parvum isolates indicated that they were of subtype families IIa and IId, including 3 of genotype IIa A15 G2 R1, and 1 of each of the following genotypes: IIa A16 G3 R1, IIa A17 G2 R1, IId A15 G1, IId A22 G1, and IId A22 G1b. The 2 C. hominis isolates were subtyped as genotypes Ia A14 R3 and Ib A10 G2. Genotyping of the $5 \mathrm{E}$. bieneusi isolates revealed the presence of 3 of genotype $\mathrm{C}$ and 2 of genotype IV. The 2 Encephalitozoon spp isolates were confirmed as E. intestinalis on sequencing of the internal transcribed spacer region.

\section{Discussion}

This study was the first to assess an in-house multiplex qPCR method for simultaneous detection of E. bieneusi, Encephalitozoon spp, and Cryptosporidium spp, which are mainly involved in opportunistic chronic diarrhea. Moreover, it provides rapid discrimination between E. bieneusi and Encephalitozoon spp, which is essential information for the initiation of targeted therapy. Multiplex qPCR showed high sensitivity at a threshold of 1 copy $/ \mu \mathrm{L}$ for each target. Interestingly, cross-reactions between Encephalitozoon spp were observed. Although these cross-reactions require the confirmation of species by sequencing, the advantage is the detection of the two other Encephalitozoon spp involved in human diseases. Moreover, the co-occurrence of the three pathogens in the same sample had no impact on the results, even if one was overrepresented compared to the others. This finding was further confirmed in the prospective study by the concurrent detection of Cryptosporidium spp. and $E$. bieneusi in the same stool sample.

The advantage of molecular tools for the diagnosis of microsporidiosis and cryptosporidiosis was previously 
demonstrated in studies showing increased sensitivity and rapid species identification. ${ }^{5,6,15-17}$ The results of the present study confirm these previous works in multiplex conditions, with a higher sensitivity of multiplex qPCR compared to that of microscopic examination. As previously reported, Cryptosporidium antigenic testing was superior to microscopy but inferior to multiplex qPCR in cases of low parasite load, with a sensitivity of $73 \%{ }^{16}$

Among the 595 analyzed stool samples, $6.1 \%$ were positive for at least one of the three targeted pathogens, corresponding to $4.2 \%$ of the patients. The overall prevalence of cryptosporidiosis and microsporidiosis were $3.07 \%$ and $1.54 \%$, respectively. Most of positive samples were diagnosed in immunocompromised patients, including solid organ transplant recipients and patients with hematologic malignancy or HIV. Two of the HIV patients were infected with cryptosporidia, whereas no cases of microsporidia infection were diagnosed. The same was observed in patients with hematologic malignancy, with the prevalence of cryptosporidiosis reaching $2.2 \%$ in hematopoietic stem cell transplantation recipients. Most of the cryptosporidiosis and E. bieneusi cases were diagnosed in kidney transplant recipients (KTRs), with prevalences of $7.3 \%$ and $2.4 \%$, respectively. These results are consistent with those from a recent study from the French National Reference Center for Cryptosporidiosis, ${ }^{18}$ which reported that KTRs constituted the main population at risk for cryptosporidiosis. Given that antiretroviral therapies are available, most cases of microsporidiosis in developed countries are diagnosed in KTRs. While few data are available from the literature, the prevalence of microsporidia seems to range from $5.8 \%$ to $11.6 \%$ in KTRs. ${ }^{19-22}$

Among the 14 cases of cryptosporidiosis, 8 isolates were identified as $C$. parvum (5 of genotype IIa, and 3 of genotype IId); 2 isolates, as $C$. hominis (1 of genotype Ia, and 1 of genotype $\mathrm{Ib}$ ); 1 isolate, as $C$. meleagridis; and 1 isolate, as C. felis. Two isolates had no species identification because of low parasite load. C. parvum IIa and IId are commonly found in Europe, especially the bovine IIa genotype. ${ }^{2}$ In contrast, $C$. hominis Ia is usually seen in developing countries, which is consistent with the history of one patient who had travelled to Mayotte. The patient carrying $C$. hominis $\mathrm{Ib}$ had traveled to Spain, where that genotype has recently been described. ${ }^{23}$ The $C$. felis isolate was identified in a HIV patient who had traveled to Mali. However, these findings are not sufficient for concluding imported cases because this species is the third most common zoonotic species encountered in France, behind $C$. parvum and $C$. hominis ${ }^{18,24}$ Interestingly, 1 isolate, from a hematopoietic stem cell transplantation recipient who had traveled to Indonesia, was identified as $C$. meleagridis and can be considered as a probable imported case, because this zoonotic species is rarely reported in France, with only four cases between 2006 and 2009. ${ }^{24,25}$

Genotyping of E. bieneusi is based on the internal transcribed spacer region sequence, with $>250$ genotypes reported to date. ${ }^{26}$ E. bieneusi genotypes can be classified into nine groups, with group 1 containing most of the genotypes infecting humans. ${ }^{26}$ To date, few data regarding E. bieneusi genotypes in France are available. In the present study, two isolates of genotype IV (frequent synonym: genotype $\mathrm{K}$ ) and belonging to zoonotic group $1 \mathrm{c}^{27}$ were identified in a pediatric liver transplant recipient and in an immunocompetent child who had traveled to Burundi. Interestingly, that genotype has been previously reported in African countries, such as Uganda, Cameroon, Gabon, and Malawi. ${ }^{28-31}$ Two isolates of genotype $\mathrm{C}$ (group 1f) were identified in adult KTRs, and one, in a liver transplant recipient. This genotype seems to be exclusively of human origin and is often isolated from solid organ transplant recipients, especially KTRs. ${ }^{19,27}$ In a retrospective study conducted in Eastern France, the presence of isolates of genotypes $\mathrm{A}, \mathrm{C}, \mathrm{D}$, and $\mathrm{S} 9$, all belonging to group 1, was reported. ${ }^{19,32}$ Interestingly, the three isolates of genotype C identified in this study were from KTRs. However, updated data on genotypes involved in other clinical contexts are required for confirming a potential link between KTR and genotype C. Finally, the two cases of E. intestinalis infection were detected in immunocompetent children who had traveled to tropical areas.

To conclude, this multiplex qPCR method allowed the concurrent detection of major opportunistic eukaryotes involved in chronic diarrhea. Based on the results from this 2-year prospective study, this tool has a place in the first-line investigation of diarrhea in immunocompromised patients, especially in KTRs, but also in immunocompetent patients.

\section{Author Contributions}

M.M. performed literature search and wrote the manuscript; M.M. and C.F. collected the data; M.M., L.F., F.D., and P.P. performed experiments; C.N., F.D., C.G., and P.P. provided critical input in writing the manuscript; P.P. conceived the study; all of the authors read and approved the final manuscript. P.P. is the guarantor of this work and, as such, had full access to all of the data in the study and takes responsibility for the integrity of the data and the accuracy of the data analysis.

\section{Supplemental Data}

Supplemental material for this article can be found at http://doi.org/10.1016/j.jmoldx.2020.12.005.

\section{References}

1. Feng Y, Ryan UM, Xiao L: Genetic diversity and population structure of Cryptosporidium. Trends Parasitol 2018, 34:997-1011

2. Xiao L: Molecular epidemiology of cryptosporidiosis: an update. Exp Parasitol 2010, 124:80-89 
3. Didier ES, Weiss LM: Microsporidiosis: not just in AIDS patients. Curr Opin Infect Dis 2011, 24:490-495

4. Hunter PR, Nichols G: Epidemiology and clinical features of Cryptosporidium infection in immunocompromised patients. Clin Microbiol Rev 2002, 15:145-154

5. Menotti J, Cassinat B, Porcher R, Sarfati C, Derouin F, Molina J-M: Development of a real-time polymerase-chain-reaction assay for quantitative detection of Enterocytozoon bieneusi DNA in stool specimens from immunocompromised patients with intestinal microsporidiosis. J Infect Dis 2003, 187:1469-1474

6. Menotti J, Cassinat B, Sarfati C, Liguory O, Derouin F, Molina J-M: Development of a real-time PCR assay for quantitative detection of Encephalitozoon intestinalis DNA. J Clin Microbiol 2003, 41: $1410-1413$

7. Verweij JJ, Hove RJT, Brienen EAT, Lieshout LV: Multiplex detection of Enterocytozoon bieneusi and Encephalitozoon spp. in fecal samples using real-time PCR. Diagn Microbiol Infect Dis 2007, $57: 163-167$

8. Hadfield SJ, Robinson G, Elwin K, Chalmers RM: Detection and differentiation of Cryptosporidium spp. in human clinical samples by use of real-time PCR. J Clin Microbiol 2011, 49:918-924

9. Henriksen SA, Pohlenz JF: Staining of cryptosporidia by a modified Ziehl-Neelsen technique. Acta Vet Scand 1981, 22:594-596

10. Ryan NJ, Sutherland G, Coughlan K, Globan M, Doultree J, Marshall J, Baird RW, Pedersen J, Dwyer B: A new trichromeblue stain for detection of microsporidial species in urine, stool, and nasopharyngeal specimens. J Clin Microbiol 1993, 31: 3264-3269

11. Mary C, Chapey E, Dutoit E, Guyot K, Hasseine L, Jeddi F, Menotti J, Paraud C, Pomares C, Rabodonirina M, Rieux A, Derouin F; ANOFEL Cryptosporidium National Network: Multicentric evaluation of a new real-time PCR assay for quantification of Cryptosporidium spp. and identification of Cryptosporidium parvum and Cryptosporidium hominis. J Clin Microbiol 2013, 51:2556-2563

12. Alves M, Xiao L, Antunes F, Matos O: Distribution of Cryptosporidium subtypes in humans and domestic and wild ruminants in Portugal. Parasitol Res 2006, 99:287-292

13. Sulaiman IM, Fayer R, Lal AA, Trout JM, Schaefer FW, Xiao L: Molecular characterization of microsporidia indicates that wild mammals harbor host-adapted Enterocytozoon spp. as well as humanpathogenic Enterocytozoon bieneusi. Appl Environ Microbiol 2003, 69:4495-4501

14. Katzwinkel-Wladarsch S, Lieb M, Heise W, Löscher T, Rinder H: Direct amplification and species determination of microsporidian DNA from stool specimens. Trop Med Int Health 1996, 1:373-378

15. Garcia LS: Laboratory identification of the microsporidia. J Clin Microbiol 2002, 40:1892-1901

16. Checkley W, White AC, Jaganath D, Arrowood MJ, Chalmers RM, Chen X-M, Fayer R, Griffiths JK, Guerrant RL, Hedstrom L, Huston CD, Kotloff KL, Kang G, Mead JR, Miller M, Petri WA, Priest JW, Roos DS, Striepen B, Thompson RCA, Ward HD, Van Voorhis WA, Xiao L, Zhu G, Houpt ER: A review of the global burden, novel diagnostics, therapeutics, and vaccine targets for Cryptosporidium. Lancet Infect Dis 2015, 15:85-94

17. Subrungruang I, Mungthin M, Chavalitshewinkoon-Petmitr P, Rangsin R, Naaglor T, Leelayoova S: Evaluation of DNA extraction and PCR methods for detection of Enterocytozoon bieneusi in stool specimens. J Clin Microbiol 2004, 42:3490-3494

18. Costa D, Razakandrainibe R, Sautour M, Valot S, Basmaciyan L, Gargala G, Lemeteil D: French national network on surveillance of human cryptosporidiosis. Human cryptosporidiosis in immunodeficient patients in France (2015-2017). Exp Parasitol 2018, 192: $108-112$

19. Greigert V, Pfaff AW, Abou-Bacar A, Candolfi E, Brunet J: Intestinal microsporidiosis in Strasbourg from 2014 to 2016: emergence of an Enterocytozoon bieneusi genotype of Asian origin. Emerg Microbes Infect 2018, 7:97

20. Kicia M, Wesolowska M, Kopacz Z, Jakuszko K, Sak B, Květonová D, Krajewska M, Kváč M: Prevalence and molecular characteristics of urinary and intestinal microsporidia infections in renal transplant recipients. Clin Microbiol Infect 2016, 22:462. e5-462.e9

21. Galván AL, Martín Sánchez AM, Pérez Valentín MA, HenriquesGil N, Izquierdo F, Fenoy S, del Aguila C: First cases of microsporidiosis in transplant recipients in Spain and review of the literature. J Clin Microbiol 2011, 49:1301-1306

22. Ghoshal U, Khanduja S, Pant P, Prasad KN, Dhole TN, Sharma RK, Ghoshal UC: Intestinal microsporidiosis in renal transplant recipients: prevalence, predictors of occurrence and genetic characterization. Indian J Med Microbiol 2015, 33:357

23. Azcona-Gutiérrez JM, de Lucio A, Hernández-de-Mingo M, GarcíaGarcía C, Soria-Blanco LM, Morales L, Aguilera M, Fuentes I, Carmena D: Molecular diversity and frequency of the diarrheagenic enteric protozoan Giardia duodenalis and Cryptosporidium spp. in a hospital setting in Northern Spain. PLoS One 2017, 12:e0178575

24. The ANOFEL Cryptosporidium National Network Collective: Laboratory-based surveillance for Cryptosporidium in France, 2006-2009. Eurosurveillance 2010, 15:19642

25. Chalmers RM, Giles M: Zoonotic cryptosporidiosis in the UK challenges for control. J Appl Microbiol 2010, 109:1487-1497

26. Santín M, Calero-Bernal R, Carmena D, Mateo M, Balseiro A, Barral M, Lima Barbero JF, Habela MÁ: Molecular characterization of Enterocytozoon bieneusi in wild carnivores in Spain. J Eukaryot Microbiol 2018, 65:468-474

27. Thellier M, Breton J: Enterocytozoon bieneusi in human and animals, focus on laboratory identification and molecular epidemiology. Parasite 2008, 15:349-358

28. Tumwine J, Kekitiinwa A, Nabukeera N, Akiyoshi D, Buckholt M, Tzipori S: Enterocytozoon bieneusi among children with diarrhea attending Mulago Hospital in Uganda. Am J Trop Med Hyg 2002, 67: 299-303

29. Sarfati C, Bourgeois A, Menotti J, Liegeois F, Moyou-Somo R, Delaporte E, Derouin F, Ngole EM, Molina J-M: Prevalence of intestinal parasites including microsporidia in human immunodeficiency virus-infected adults in Cameroon: a cross-sectional study. Am J Trop Med Hyg 2006, 74:162-164

30. Breton J, Bart-Delabesse E, Biligui S, Carbone A, Seiller X, OkomeNkoumou M, Nzamba C, Kombila M, Accoceberry I, Thellier M: New highly divergent rRNA sequence among biodiverse genotypes of Enterocytozoon bieneusi strains isolated from humans in Gabon and Cameroon. J Clin Microbiol 2007, 45:2580-2589

31. Ten Hove RJ, Van Lieshout L, Beadsworth MBJ, Perez MA, Spee K, Claas ECJ, Verweij JJ: Characterization of genotypes of Enterocytozoon bieneusi in immunosuppressed and immunocompetent patient groups. J Eukaryot Microbiol 2009, 56:388-393

32. Desoubeaux G, Maakaroun-Vermesse Z, Lier C, É Bailly, Morio F, Labarthe F, Bernard L, Chandenier J: Successful treatment with fumagillin of the first pediatric case of digestive microsporidiosis in a liver-kidney transplant. Transpl Infect Dis 2013, 15:E250-E259 